Books, videos, cd-roms, dvds and any other relevant items submitted for a review in the BDJ should be addressed to:

Mike Grace, Editor, British Dental Journal,

64 Wimpole Street WIG 8YS

\section{History of Periodontology}

F. Carranza and G. Shklar (Eds)

Surrey: Quintessence, 2003

price $€ 29$, pp224

ISBN 0723431868

The quality of books published by

Quintessence is high both in

presentation and editing, and it has

become a privilege to be asked to review

a new publication, allowing the reviewer

to concentrate on the authors and their

intentions. Here, Fermin Carranza and

Gerald Shklar have produced a labour of love, and throughout they reveal their enjoyment of, and pride in, their chosen specialty.

The book shows that care, rather than cure, of the oral environment, has a history as long as records can be found. Not only that, but periodontology has attracted those practitioners who are temperamentally inclined to take the long view, and who have to make treatment decisions which only show their worth after years. As a result it makes an ideal subject for a history, as successes and failures in research and treatment are revealed by time.

In the foreword, S.Sigmund Stahl laments that students are unaware of the history of dentistry. The more appropriate term is perhaps unawakened, since the student of dentistry is by age and need for technical training the subject of total immersion in the present. Then, as with radiology and dental materials, other specialties which do not necessarily appeal to the undergraduate, periodontology is quickly found to be at the very heart of successful general dental practice, both as a practice builder, and as the source of perhaps the largest part of job satisfaction when looking back on a dental career. The importance of this book featuring on every student's reading list, is to install background data, so that when the novice has begun to master the here and now, the value of what they have been told about the past can begin to grow, as they begin to comprehend the reality of their future.

The book is a collection of 29 chapters by the authors, divided into five sections, of which the longest is the last, covering the 20th century. The others describe prehistory and early civilisations, the classical and mediaeval ages, the modern era (early modern being the Renaissance Period) and the 19th century. An epilogue by Ray Williams looks to the future.

While the later essays are understandably biased towards the American experience, this does not mean that the significant contributions of operators widely spread in the world are overlooked, three among 'our' team being Sir John Tomes, Sir William Hunter, (around whom the focal infection controversy swirled at the beginning of the twentieth century), and Sir Wilfred Fish.

The table of contents provides a quick access guide, each chapter ends with a references list, and there is a picture credits list, a persons index and the standard index. The word periodontal has changed its meaning over time, and a dated glossary of terms is the only significant omission.

I recommend this book not only as a standard student text, but also as a thoroughly readable and profitable book for the specialist and general dental practitioner.

M. Bishop

\section{Tyldesley's Oral Medicine, 5th Edition}

\section{A. Field and L. Longman \\ Oxford: Oxford University Press, 2003 \\ price $€ 32.50$, pp243 \\ ISBN 0198631470}

The authors and Oxford Medical Publications are to be congratulated on the 5th edition of Tyldesley's Oral Medicine. This 5th edition has significantly changed and improved upon the previous edition. Many will remember the original book which was highly narrative in its style with virtually no illustrations. This latest 5 th edition has been substantially altered with a pleasing number of high quality colour illustrations along with a readable and easy to use layout, including a significant number of key messages and easy to understand tables.

The text is quite long at nearly 250 pages and there has been a significant attempt to broaden the scope of the 5th edition. The initial chapter is devoted to the oral mucosa including its normal structure, and it is probably over ambitious to include all this information in sufficient detail in 61/2 pages. There are also useful chapters on the assessment and investigation of patients although, again the information included is so extensive that some of it is inadequately explained. For example, there is very little explanation of why certain immunological tests are indeed useful in the clinical situation. There is also a chapter on therapy which brings together the generic information in prescribing for oral mucosal disease which I am sure will be very popular with students, and there are then a number of disease orientated chapters all of which are well written and informed, and the benefit of having specialist advisers for different sections of the book is quite clear.

There is, of course, the obligatory upside down photograph in figure 5.5 and last minute alterations have created small errors such as substituting figure 8.7 for table 8.11 in the text and disappointment that there is no figure 8.8.

Notwithstanding these minor observations, the text is well written, well illustrated, and well laid out, and the 5 th edition represents a significant improvement on what has already become a popular and standard oral medicine text. 

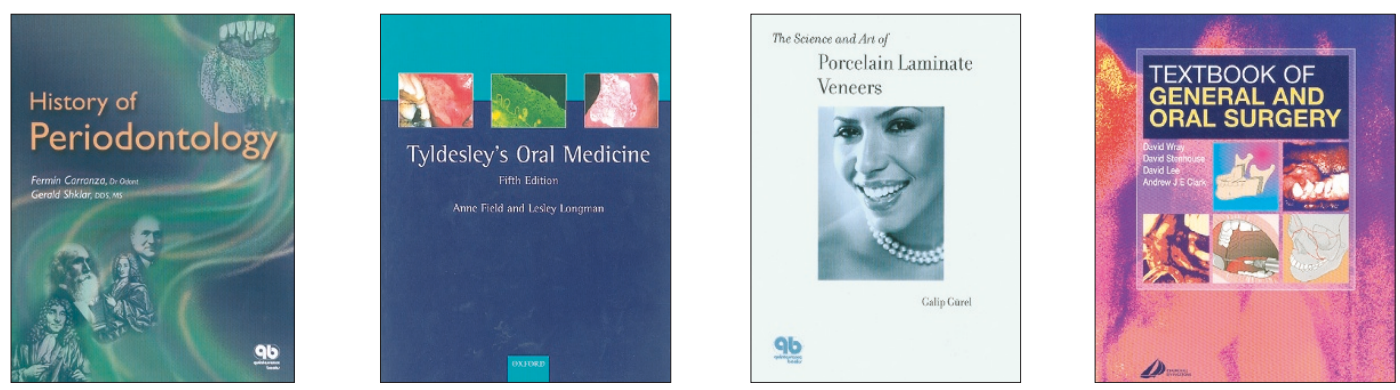

\section{The Science and Art of Porcelain Laminate Veneers}

\begin{tabular}{l}
\hline G. Gurel (Ed) \\
Surrey: Quintessence, 2003 \\
price £138, pp528 \\
ISBN 1850970602 \\
\hline
\end{tabular}

This large and weighty text book is designed for reference from the shelf or table-top, not the pocket! The text runs to 517 pages and includes numerous good quality colour illustrations, including line drawings and clinical photographs, which would also prove valuable for in-surgery patient education. The text font is large and easy to read.

The work is divided into fourteen chapters including aesthetics, adhesion, colour, clinical procedures, failures, periodontal considerations, adjunctive orthodontics and patient education and management. Each chapter concludes with an extensive bibliography, which includes up-to-date references but extends over a large date range. The main contents list is comprehensive. The index is sufficiently detailed to allow the reader easy navigation through the text.

The main author is of Turkish origin and contributions are made by six additional authors but the translation is of good quality. However, a number of typographic errors were noted being more common in some chapters than others. As is often the case, the style of the authors differs and some chapters are easier to read than others. American spelling is used throughout.

The author defends and promotes aesthetic dentistry and emphasises the role of dental aesthetics on patient's morale and self-esteem. However, dental and facial harmony is recommended firmly and the author rightly deplores the 'whiter-than-white' dentition.

Throughout the text, emphasis is placed on communication and treatment planning and all aspects of tooth preparation, bonding and finishing of porcelain laminate veneers are covered. A chapter on failures is usefully included.

In the reviewer's experience, veneer removal is extremely difficult if enamel is to be conserved yet all porcelain and resin removed, and some readers may feel that these difficulties are under-stated in the text. The author predicts that porcelain laminate veneers will become increasingly used, and this may well be the case. However, in the reviewer's practice, porcelain veneers are becoming less frequently employed as alternative techniques and materials improve.

Despite this, porcelain veneers have their indications and practitioners will find much of interest in this book. Moreover, several chapters will prove useful for general reference, in particular those covering aesthetics, colour and adhesion. It is likely that the number and quality of the colour illustrations have dictated the cover price.

S. Dunne

\section{Textbook of General and Oral Surgery}

\begin{tabular}{l}
\hline D. Wray, D. Stenhouse, D. Lee and A. J. E. Clark \\
London: Churchill Livingstone, 2003 \\
price $£ 32.99$, pp322. \\
ISBN 0443070830
\end{tabular}

ISBN 0443070830

The Textbook of General and Oral

Surgery is organised into two main parts and consists of 38 chapters and has 18 contributors. The first part is further divided into two sections with basic principles in general surgery and specialist surgical principles. The second part is dedicated to topics in oral surgery. It provides current information, is simple to read, and is reasonably well

illustrated.

It is refreshing to read sections on the principles of general surgery, written mainly by general surgeons, and oral surgery condensed into a book consisting of only 322 pages. The general surgery section covers a range of topics including wound healing, fluid balance, crossinfection, sepsis, fractures, anaesthesia and sedation. The chapters are well laid out and consist of several relevant main headings, which have been further subdivided into smaller but very informative subheadings relevant to the topic being discussed. This section provides the reader with a general understanding of the basic principles of surgery.

The chapters on specialist surgical principles cover a wide range of topics including facial fractures, orthognathic, salivary, cleft lip and palate, TMJ surgery, and orofacial malignancy. The chapters on plastic, ENT and neurosurgery are very useful. The size of the chapters mean that the topics are not covered comprehensively; however, the core information required at undergraduate and early postgraduate levels are provided.

A subsequent section on oral surgery covers the range of topics very relevant to all stages of undergraduate and postgraduate oral surgery education. The authors should be praised for the way they have managed to minimise duplication between this section and the general surgery section. However, the chapter on history and examination (chapter 22) probably makes chapter two (history taking) irrelevant. Again the chapters are very well presented with multiple relevant subheadings, which are short and informative.

Throughout the book the chapters are laden with highlighted tables, which are concise, and the reader would find very useful. The quality of the images presented are reasonable and the drawings are informative. Colour has been added to the text throughout the book making it easy reading on the eyes. One criticism of this textbook is that as we live in an era of pursuing evidence based practice it would have been very useful to have list of references at the end of most chapters.

This book is valuable especially for those in undergraduate years and forms a quick reference book for those in postgraduate training in oral surgery. V. Sivarajasingham 